\title{
Bergsoniana
}

$1 \mid 2021$

Reassessing Bergson

\section{Bergsonian Answers to Contemporary Persistence Questions}

Florian Fischer

\section{(2) OpenEdition \\ Journals}

Electronic version

URL: https://journals.openedition.org/bergsoniana/448

DOI: 10.4000/bergsoniana.448

ISSN: 2800-874X

Publisher

Société des amis de Bergson

\section{Electronic reference}

Florian Fischer, "Bergsonian Answers to Contemporary Persistence Questions", Bergsoniana [Online], 1 | 2021, Online since 01 July 2021, connection on 08 November 2021. URL: http:// journals.openedition.org/bergsoniana/448 ; DOl: https://doi.org/10.4000/bergsoniana.448

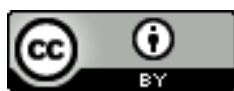

Les contenus de la revue sont mis à disposition selon les termes de la Licence Creative Commons Attribution 4.0 International. 


\title{
BERGSONIAN ANSWERS TOCONTEMPORARY PERSISTENCE QUESTIONS
}

\author{
Florian FISCHER
}

\section{Introduction}

Time is one of the central topics of contemporary analytic philosophy, and Henri Bergson is one of the most important philosophers of time, but still Bergson plays virtually no role in the contemporary analytic debate about time. In contrast to his poor reception, ${ }^{1}$ Henri Bergson has a lot to offer analytic philosophy, as I will argue. More precisely, I will illustrate what the debates about persistence and ontology of time might gain from incorporating Bergsonian ideas.

To do so, I will first investigate persistence, i.e., existence through time. The focal point of the contemporary analytic debate is how to conceptualise change without letting the involved incompatibilities lead to a logical contradiction. This can be called a horizontal way of posing the question, namely, how to reconcile two incompatible properties had by one entity at two points in time.

Bergson famously asserted that objects are ontologically secondary, minddependent abstractions from an underlying dynamic reality. This opens up the possibility to develop a novel account of persistence. As this

1. An account of why Bergson is so poorly received within the contemporary analytic debate is beyond the scope of this paper. The infamous division into "analytic" and "continental" philosophy clearly is an important factor in this regard (Chase and Reynolds 2010, ch. 2) and especially Bertrand Russell might have played a significant part (Vrahimis 2011). 
theory, which I call produrantism, focuses on the abstractions, it can be characterised as a vertical account.

The contemporary analytic debate about persistence usually assumes eternalism, i.e., that all times are ontologically on a par. This assumption is far from unproblematic, however. Thus, the debate about persistence must be discussed in the wider context of temporal ontology. Here Bergson's famous critique of the spatialisation of time, i.e., our tendency to confuse our (spatial) representations of time with time itself, may help to overcome the eternalistic restriction. ${ }^{2}$

\section{Red at t1; Blue at t2: Persistence According to the Contemporary Analytic Debate}

The contemporary analytic debate about persistence is de facto a debate about change. ${ }^{3}$ Virtually all objects change during their existence. For an easy example think of a mood light changing its colour from red, say at $\mathrm{t} 1$, to blue, say at $\mathrm{t} 2$. If we depict time horizontally from left to right, the whole situation looks like figure 1 .

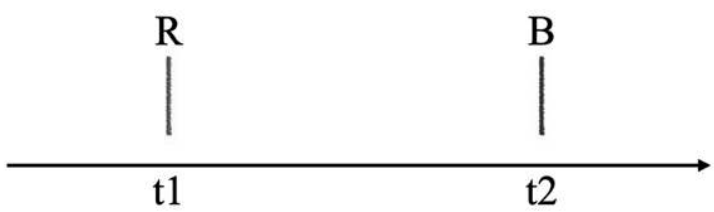

FIGURE 1. Red at $\mathrm{t} 1$ and blue at $\mathrm{t} 2$.

The first thing to note is that not all combinations of properties are sufficient to constitute change. Of course, the properties involved need to be different, because staying red would be a case of stability, not of change. Likewise, the properties involved in a change need to be incompatible, i.e.,

2. I do not claim that we take time to be spatial because the representations we use are spatial. This would indeed be a fallacy. Mellor has convincingly argued against this inference (Mellor 2012, 164). But this is not what is at stake. I take the wide-spread spatial representations of time only as indicator of the often implicit, uncritical assumption of spatialised time.

3. I will speak rather indiscriminately of the problem of persistence in this paper. However, I think that what is usually discussed under this heading, namely, how to conceptualise change, is only part of persistence. Cases of stability are clearly also cases of persistence, and a comprehensive account of persistence needs to include them as well (Fischer 2017). 
being red must exclude being blue in a way in which being square does not.

Incompatible different properties, like red and blue, are still not enough to characterise change, because, to say it with the words of Hugh Mellor, "change needs identity as well as difference" (Mellor 1998, 98). This is so because change needs to be differentiated from exchange. Ontologically, it makes a difference whether one entity changes or whether it is exchanged with another entity, even if this second entity is very similar to the first one.

If one entity exemplifies incompatible properties, a contradiction is right around the corner. Is not the mood light in our example red and non-red (by being blue)? Most philosophers agree that even in cases of change a full-blown logical contradiction needs to be avoided. Thus, the heart of the contemporary debate about persistence is how to conceptualise change in such a way that the involved incompatible properties do not lead to a contradiction regarding the persisting entity.

The mainstream analytic debate about persistence ${ }^{4}$ can be split up into two camps: endurantistic and perdurantistic solutions. ${ }^{5}$ Endurantism is supposed to be more intuitive than perdurantism, because it does not tamper with the everyday conception of objects. Enduring objects are three-dimensional. They exist through time by being wholly present at each moment of their existence and, thus, they are multi-located in (space-) time. ${ }^{6}$ According to perdurantism objects are four-dimensional, extended in time as well as in space.

A number of different endurantistic suggestions have been proposed to avoid the looming contradiction in the context of change. One strategy is to put a time index on the having of the relevant properties, either by time-indexing the copula $\left(\right.$ is $_{\mathrm{t} 1}$ ) (Johnston 1987,129 ) or adding a temporal adverb (t1-ly) (Haslanger 1989). Another strategy would be to interpret the situation using non-contradictory relations (Lewis 1986, 204). The mood light in our example would thus stand in the red-relation to $\mathrm{t} 1$ and

4. In the context of this paper, I can only briefly sketch the contemporary analytic debate about persistence. I have spelled out the different accounts in detail elsewhere (Fischer 2016, 13).

5. We owe this well-known account of the different camps to David Lewis (Lewis 1986, 204).

6. "Multi-location" is a terminus technicus. For our purposes it is sufficient to characterise it as having more than one exact location. For more on multi-location see (Costa et al. 2020). 
in the blue-relation to t2. Yet another version of endurantism would be to take a three-place relation of property-exemplification (Meixner 2006, 95), which combines objects, times and properties. This relation would then hold for our mood light $\mathrm{t} 1$ and red, as well as for the mood light $\mathrm{t} 2$ and blue. No contradiction arises here either.

Perdurantism can be understood as putting a time-index on the object itself, splitting it up into different (temporal) parts. This may seem unintuitive, but it does avoid the looming contradiction. The incompatibility of the properties involved is only problematic if they are had by the same entity but, following perdurantism, the temporal parts are the primary property bearer. So, in our example there is a red temporal part (tp1) and a blue temporal part (tp2), according to the perdurantist, but as these are not identical, no contradiction arises. Furthermore, if both are part of the same perduring object $(\mathrm{OP})$, we have change (see figure 2), if not exchange. ${ }^{7}$

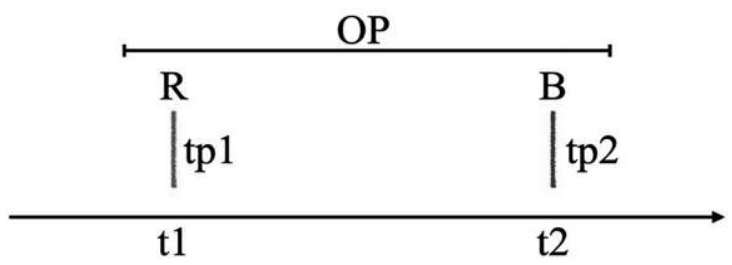

FIGURE 2. Depicting perdurantism

Taking a bird's-eye view on the debate about persistence reveals a shared assumption of all the accounts I have sketched so far. The debate takes incompatible properties exemplified at different times as its contentual starting point. Or, to put it even more plainly, the debate starts with red at $\mathrm{t} 1$ and blue at $\mathrm{t} 2$ (remember figure 1). Persistence in contemporary analytic philosophy is a purely horizontal question: How to reconcile the incompatibility of the properties at $\mathrm{t} 1$ and $\mathrm{t} 2$ with the fact that they (in some way or other) belong to the same entity. ${ }^{8}$

7. One might think that perdurantism is a dissolution rather than a solution of the problem because at each point in time there is only the respective temporal part and thus no strict identity over time. But this is controversial within the perdurantist camp. Ted Sider, for example, asserts that also the whole is located at each point in time (Sider 2001, 54).

8. Another, widely ignored question, is how the incompatible properties got to be there in the first place. That is, what are the change-makers? What (metaphysically) makes it 
With this level of abstraction in view, we can now try to think about a novel contribution to the debate, which is not just another variation on what has already been given, not just a further idea where to put the time-index. It is at this point that the work of Henri Bergson becomes relevant, who argued that the "objects" (as well as the properties) about which I have been speaking so uncritically are actually mind-dependent abstractions from an underlying, ongoing, processual reality. This, of course, needs to be spelled out - and I will do so in the next section. The main idea is that with Bergson we can focus on the vertical question, namely how the abstractions relate to the underlying reality. I will argue that this understanding also provides an answer to the horizontal question.

\section{Tackling the Problem of Persistence with Bergson: Boon and Bane of Abstractions}

In this section, I want to illustrate how one of Bergson's central ideas can help to develop a novel kind of solution to the problem of persistence. At first, it might seem that the Bergsonian distinction between abstractions and the underlying processes is irrelevant, because it is diagonal to the problems discussed in the contemporary debate about persistence. But quite contrarily, this very feature allows for the development of a novel solution that is not just another slightly tweaked endurantism or perdurantism. On top of that, it allows for a broader scope of application, because the presented solution is not just tailor-made to solve a specific philosophical problem but derived from more general considerations.

Bergson criticises the very notions of objects and properties at a fundamental level. According to him, if one looks more closely, one can see that what is called "object" is actually only a relatively stable entity. Even in the most solid entities there is more change than one initially suspects. And perhaps even more surprisingly, the same holds true for properties. Following Bergson, every quality in the end is change.

Very roughly, Bergson holds that we take something like snapshots from an underlying, ever-changing reality. We do so because we are actors, i.e., we need the stable snapshots to plan and evaluate our actions in the world. It is an illusion, however, to confuse this picture of the world, which is largely due to our access to it, with reality itself. We mark off relatively isolated systems and then call them "objects," and we do so by means

that the mood light changes from red to blue. I take dispositions to hold an important role in answering this question (Fischer 2020). 
of qualities, which themselves decompose "into an enormous number of elementary movements" (Bergson 1911, 326-327).

Take the most popular example of an "object" in philosophy nowadays, a table. Although tables seem pretty enduring, they actually change all the time. Every use leaves micro-scratches behind, and even if they are not used, the surface is always made up of different atoms. But this is not only the case for tables. Even crystals, the epitome of stability, grow and disaggregate over time. ${ }^{9}$

Note that this need not be understood as a degradation of objects. First of all, one can take objects ontologically seriously and need not question their reality. The assertion that objects do not occur on the fundamental ontological level does not imply that objects do not occur on any level of ontology. ${ }^{10}$ But also, for practical purposes, one need not demote objects, given this outset. Bergson explicates the usefulness of object-thinking at length. He acknowledges modern science without reservation, although it is based on the aforementioned static snapshots of reality. Beginning with a complex and dynamic reality, we block out most of the multifarious aspects. The problem is that in the process of abstraction something essential goes missing.

This rough and ready characterisation of abstractions is sufficient for the question that concerns this paper, namely the potential impact on the debate about persistence. We will leave aside the exegetical correctness and overall tenability of the account for now. Let us instead return to the problem of persistence and see how Bergson's account of abstractions applies to it. ${ }^{11}$ Reconsider our earlier example of the change from red to blue. The objects (as well as the properties) involved in this change are abstractions, following Bergson. We pick out the mood light as a relatively

9. With qualities it is a little trickier, but the status of abstractions of the properties is not especially important in our context, so we can bracket it.

10. This corresponds to the distinction between reduction and elimination from philosophy of mind (see e.g., William 2020). Basically, one could either completely eliminate mental properties from ontology or reduce them to physical. The same goes for objects in our context; they can either be eliminated from ontology or reduced to underlying processes. The difference is that they are still part of ontology according to the reductive strategy, albeit not ontologically fundamental.

11. Bergson's treatment of individuality may offer a shortcut to avoiding the problem of persistence. Because there is constant change, there is never full individuality (Bergson $1911,16)$. It follows from this that identity over time cannot be ascribed. At best, one might argue, identity would come in degrees, but the problem of persistence needs strict identity to arise. 
stable system and ascribe redness to it. Given the distinction between abstractions and the underlying dynamic reality, we can develop a novel account of persistence. Instead of objects, this account posits processes at the ontologically fundamental level and hence was called "produrantism." 12 Now, following produrantism, the underlying processes are the actual persisting entities. The primary property bearers are abstractions from these processes, and, hence, they are not identical to the processes themselves. The important thing is that the two abstractions involved are not identical to each other $(\mathrm{a} 1 \neq \mathrm{a} 2)$ either, and thus red and blue are not exemplified by the same entity (see figure 3).

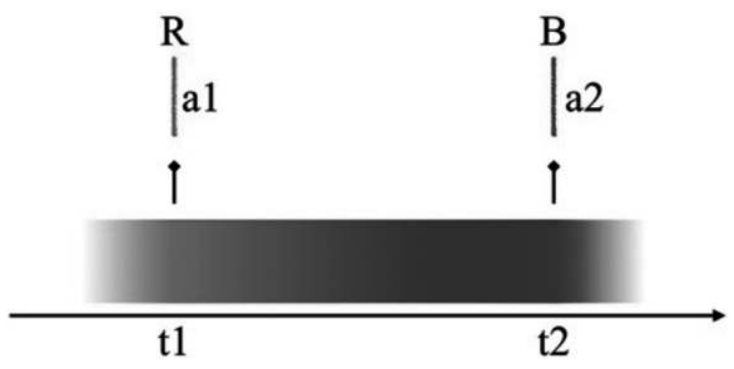

FIGURE 3. Depicting produrantism

One might notice that produrantism's answer to the problem of persistence has the same structure as perdurantism: ${ }^{13}$ The contradiction is avoided by the involvement of more than one primary property bearer (tp1 and tp2 in the case of perdurantism; a1 and a 2 in the case of produrantism). This, of course, does not mean that produrantism de facto is perdurantism. The positions only have the same structure; the way they are metaphysically spelled out is quite different. Produrantism and perdurantism also have a

12. I coined the term "produrantism" (Fischer 2017). As is the case with perdurantism and endurantism, produrantism is not one account, but a family or camp of accounts. While it is built in the same general spirit, Anne Sophie Meincke holds a version of produrantism quite different from my account (Meincke 2019). Also, Johanna Seibt's recurrence theory is located in the produrantist camp (Seibt 1990; 2007).

13. The elaboration of the structure of the perdurantistic account goes back to Jeffery Brower (2010). Brower himself has devised a version of endurantism which is structurally identical to perdurantism, i.e., the primary property bearers at different times are neither identical to the persisting entity nor to each other. The metaphysical flesh to these structural bones, however, is quite different, as Brower's account is deeply rooted in Aristotelian hylomorphism. 
very different scope of application. Whereas perdurantism is only intended as a solution to a specific philosophical problem, the distinction between abstractions and the underlying process is much more general. The solution to the problem of persistence comes out as a side-effect, so to say.

Having shown how the contradiction is avoided, we also need to consider the distinction between change and exchange in the produrantistic picture. On the classical account, change concerns one object with incompatible properties, while exchange concerns more than one object. Conceptually, we can still uphold the difference between change and exchange, given produrantism. Yet in contrast to the classical accounts, both concepts can be applied to the same physical situation according to produrantism. This is so because the classical accounts assume objects on the fundamental ontological level. Thus, given a specific situation, the number of objects is fixed, and therefore it is also fixed whether this situation is a case of change or exchange. Produrantism's flexibility in the application of the concepts change and exchange is a feature, however, not a bug! Take the example of someone being shot. Assume, for the sake of simplicity, that they die right away. Is this a case of change or of exchange? On the one hand, a living person goes out of existence, and a corpse comes into existence, which is an exchange. But regarding the lump of matter on the other hand, the bullet hole is only a minor change: The corpse has nearly the same mass, position, etc. and consists of the same matter. There is no inherent contradiction in applying both concepts, change and exchange, to the same physical situation, and the resulting descriptions are actually quite close to our everyday rendering of the situation.

As an interim conclusion, we can say that produrantism is a viable solution to the problem of persistence: It avoids the contradiction in the context of change and gives a satisfactory answer regarding the difference between change and exchange. In stark contrast to the rest of the accounts in the contemporary debate about persistence, produrantism brings what I have called the vertical question into consideration. This is possible because produrantism does not take objects as ontologically fundamental but respects the Bergsonian idea that objects are abstractions from an underlying dynamical reality.

Bergson's attack on the standard account of objects and properties is not an isolated stance but is part of an overarching campaign against the uncritical assumption of spatialised time. In the next section, I will expound what spatialisation of time is and why Bergson criticises it. This in turn questions the fundament of the debate about persistence. The way the debate about 
persistence is usually framed presupposes eternalism. I will show why this presupposition is dubious and how we might overcome it if we reject spatialised time in fundamental ontology.

\section{Non-spatialised Time: Beyond the Eternalistic Limitation}

Eternalism is standardly, if often tacitly, assumed in the contemporary debate about persistence, and this assumption is taken to be unproblematic. Either eternalism is simply taken for granted or it is chosen for ease of illustration (Balashov 2010, 11). But eternalism does not really provide an equal ground to compare theories of persistence. Not only has it been argued (Benovsky 2007) that eternalism is biased towards perdurantism, ${ }^{14}$ but eternalism is also in tension with a central conviction many nonperdurantists hold, namely that temporal becoming is absolute. ${ }^{15}$

I will unearth a common root of the belief that the eternalistic assumption is unproblematic and the implicit preference of certain theories of persistence in the contemporary analytic debate about persistence. What Bergson calls spatialisation of time actually pertains to and affects both, the debate about the ontology of time and the debate about persistence, or so I will argue.

According to Bergson, our concept of time consists of two parts: durée and space. I use "durée" as a terminus technicus because the translation "duration" comes with the wrong connotations. Duration sounds like something enduring (in the non-technical sense), something staying in existence. Durée, however, has almost the opposite meaning for Bergson. Durée "means invention, the creation of forms, the continual elaboration of the absolutely new" (Bergson 1911).

Now, Bergson asserts that "time, understood in the sense of a medium in which we make distinctions and count, is nothing but space" (Bergson 1910, 91). Basically, there are two ways of counting: you could either directly count objects in space, for example by marking them off one by one; or you could represent them in an ideal space. Then you (mentally)

14. Marcello Oreste Fiocco even goes one step further and argues that what he calls ontological homogeneity, namely that "all moments in time have the same ontological status" is only compatible with perdurantism (Fiocco 2010, 66). While I agree with much of his paper, I still think that its demarcation criterion is slightly off. As I will argue below, the moving spotlight theory is "guilty" of spatialising time, although it clearly rejects Fiocco's ontological homogeneity thesis.

15. Roughly, "absolute becoming" is the idea that events happen in a non-relative sense. For a critical examination of this concept see Savitt (2002). We will come back to the concept later in this article. 
place them in a homogenous medium. The important part is that you juxtapose the objects in order to count them, i.e., you put them together next to each other. Juxtaposition is the defining criterion of space, so, contrary to what one might think, Bergson argues that counting always involves space - either directly or via a mental act. If you ever had only one object, then the number could not increase, and hence there could be no counting. You need the former objects (or their representations, or the memory, ...) next to the present object.

This explains why Bergson asserts that time, understood as the medium of counting, is only space. The conditional character of this statement cannot be overemphasised. Spatialised time is but one aspect of time. One of the central points in Bergson's work, perhaps the central point, is that there is another aspect of time: durée, real duration. Of course, we cannot hope to discuss this concept exhaustively in this context but let me try to illustrate the differentiation of durée and spatialised time.

If you hear the bell from a nearby tower ringing, there are two things you can do, according to Bergson. You can either count the tolls or you can listen to the melody. Conceptually, one excludes the other. If you count the tolls, you necessarily abstract away from the individual characteristics of the tolls. They must be considered as the same and distinguished. You need to consider them external to each other to arrive at a number. But if you want the melody to unfold, you cannot separate the tolls and you cannot ignore the individual characteristics of the tolls. While space is associated with quantitative multiplicity, as in counting, the melody to the bell forms another kind of multiplicity: qualitative multiplicity. Qualitative multiplicity, then, is associated with durée for Bergson.

Given that there is an asymmetry between these two aspects of time, since durée is more fundamental than spatialised time, one might wonder whether spatialised time really is time. But this is beside the point. Whether you stigmatise spatialised time as distorted time, or even insist that it is not really time anymore; this is just a haggle about words. The decisive point is that there is durée, real duration, for Bergson, and that it would be misguided to base the philosophical investigation into time just on spatialised time. Spatialised time is acceptable (and even advantageous) for everyday planning and science, but at the latest when it comes to metaphysics, when we are occupied with ultimate reality, we must investigate durée.

The focus of this paper is not on Bergson's ideas themselves, but on their possible implications for the contemporary analytic debate about time. 
So, I will now turn to the alleged benefit of the Bergsonian differentiation of durée and spatialised time for the debates about persistence and the ontology of time. ${ }^{16}$

The contemporary analytic debate about persistence (implicitly) assumes eternalism, as we have noted. The remainder of this article will introduce eternalism and the associated debate about the ontology of time, and then outline the possible implications of Bergson's critique of spatialised time in this context. Lastly, we will return to the debate about persistence to evince the bias of eternalism and spatialised time and how to overcome it.

The debate about the ontology of time can be understood as a debate about which times are real. ${ }^{17}$ There are four main positions in the contemporary analytic debate: presentism, eternalism, moving spotlight theory and growing block theory. The two major positions are also the "extreme" positions: eternalism and presentism. According to presentism, only the present is real, whereas all times, past present and future, are ontologically on a par according to eternalism. The growing block theory (GBT) can be seen as a middle position between eternalism and presentism, as it asserts the reality of the past up until and including the present but denies the existence of the future. The name-giving metaphor of the moving spotlight theory (MST) is that of temporal "spotlight" highlighting one time after the other as the present. Thus, the MST could be captured as a combination of eternalism and presentism: MST holds that all times are real (as does eternalism), but also posits an ontologically special status of the present (as does presentism).

The debate about the nature of time is quite complex, so that we cannot go into detail here, but eternalism is clearly in the spirit of spatialised time. According to the eternalist, all times are ontologically on a par; and all

16. The rest of this section may be understood hypothetically, since I have not argued for the idea of spatialised time. Rather, the aim is to motivate further research into the intersection of Bergson's work and contemporary analytic philosophy of time. Actually, if the implications of accepting the Bergsonian differentiation of durée and spatialised time are plausible, this would be a good reason to accept the distinction in the first place. 17. There are different ways to frame the debate about the ontology of time. Some people talk about non-present times and others about non-present objects or objects located at non-present times. The status of these non-present entities is also discussed under different headings: sometimes the debate is about their existence and sometimes about their reality. I do not take these differences to be insignificant, but I cannot discuss them in the context of this paper. For more on this see Fischer (2016, 4-8). Hence, I will switch between the different formulations more or less indiscriminately. 
objects, past, present and future, exist. This entails a juxtaposition in the strongest sense. Following eternalism, all entities, be they points of time or objects, must be considered together and beside each other.

MST too assumes the coexistence of all moments and thus also presupposes spatialised time. The difference is that defenders of MST also believe that some times/objects are ontologically distinguished from others, namely the present ones. But the MST-way of marking the present against a background of non-present entities already requires juxtaposition in the Bergsonian sense.

This points to something crucial: the ideas of juxtaposition and spatialisation are much broader than just accepting more than one moment. To posit the ontological coexistence or coreality of multiple times, as eternalism and GBT do, is admittedly to juxtapose these times and thus to spatialise time, according to Bergson. But there are other ways to spatialise. Even a seemingly dynamic view of time according to which ever only one but ever a different moment of time, the "present," is ontologically distinguished from a background of proto-times constitutes a way of juxtaposing and hence spatialising. Every distinction presupposes the prior being-on-a-par of entities, of which some are then distinguished. Being-on-a-par, however this be specifically conceived, somehow necessarily implies a quantitative plurality of entities; and to posit a quantitative plurality of entities is necessarily to leave the realm of pure durée.

Now we can see that Bergson's critique of spatialised time does not cut exactly parallel to the division of the debate about the nature of time into presentism, eternalism, MST and GBT. Rather, it depends on how the positions are spelled out. As we have seen, eternalism and MST presuppose spatialised time, but there are spatialised versions of presentism too. ${ }^{18}$ Basically whenever temporal existence, be it of moments themselves or of objects at moments, is understood in a relative manner, i.e., relative to some background, the account in question spatialises. Standardly, however, presentists posit "absolute" becoming. Even without further spelling out the notoriously hard to grasp concept of absolute becoming, it is clear that it excludes spatialisation already at a very basic level and that the uncritical assumption of spatialised time thus disadvantages the standard versions of presentism.

The same goes for GBT: Although there are versions which end up defining time in a relative manner and thus count as spatialisers, according to most

18. Like Orilia's moderate presentism (Orilia 2016). 
GBT-accounts the future is not something which is given in some way and then only becomes actualised. Already the characterisation of GBT by C. D. Broad makes this clear: "[T] he essence of a present event is not that it precedes future events, but that there is quite literally nothing to which it has the relation of precedence" (Broad 1923, 66). Equally, the same is asserted by contemporary representatives of GBT: "There thus always is an edge of becoming beyond which there is literally nothing in time which is as yet to come" (Correia and Rosenkranz 2018, v). Thus, according to most versions of GBT and presentism, temporal existence is not something relative; but it would have to be if spatialised time were all we had. ${ }^{19}$

Likewise, the "problem" of persistence can only arise in the context of spatialised time. If you think about $\mathrm{t} 1$ and $\mathrm{t} 2$ together and next to each other, you juxtapose them. If you only ever have the present, no contradiction can arise in the first place. At the same time the uncritical assumption of spatialised time gives an advantage to accounts that incorporate a relative understanding of change. This is where the true power of Bergson's critique of spatialisation unfolds, as perdurantism requires spatialised time. ${ }^{20}$ So, while endurantism is at least expiable given eternalism and hence spatialised time, perdurantism is incompatible with real durée. It is only due to the uncritical assumption of spatialised time that perdurantism is considered an attractive, or indeed viable account of persistence.

A relative definition of change is a sine qua non for perdurantism. The defining criterion of perduring objects is that they are extended in time and consist of multiple temporal parts. The concept of extension would be taken ad absurdum if it is necessarily zero as well as the concept of part would, if there is necessarily ever only one. There is nothing in endurantism, though, that requires juxtaposition of multiple times or proto-times. ${ }^{21}$ In principle, endurantism is open to an absolute definition of change. That the debate about persistence de facto has been a debate about how to relativise the

19. Bergson's distinction between pure durée and spatialised time explains why some people have thought that presentism cannot even be spelled out consistently (Sider 2001, 64). If spatialised time is presupposed, this is no wonder.

20. It is sometimes claimed that perdurantism is incompatible with presentism; or that it requires eternalism. With the concept of spatialised time we can be more precise: perdurantism requires juxtaposition of different times and can only be spelled out in spatialised terms.

21. Obviously, also produrantism does not require a relative definition of change. In principle, it is compatible with relative change, but it unfolds it true potential if pared with non-spatialised time and absolute change. 
concept of change, i.e., where to put the temporal index, is due to the uncritical assumption of spatialised time.

The contemporary analytic debate about persistence was never fair because the central question was framed in a way that only allowed relative definitions of change as an answer. This was no problem for perdurantism, as it follows from its central conviction; but it restricted endurantism to certain forms that might not have been its strongest versions. ${ }^{22}$ Bergson's critique of spatialised time has revealed this bias in the debate. Overcoming it, however, does not even out the scales, but makes perdurantism untenable. This, of course, is only half the story. After the explanation of the partiality of the contemporary debate about time, positive accounts of persistence and the ontology of time which do not presuppose spatialised time would have to be developed. One must be careful not to slip back into vocabulary and images of juxtaposition, which is not so easy because they pervade ordinary and scientific language. ${ }^{23}$ Such a task naturally transcends the possibilities of a paper like this but let me point out that Bergson's characterisation of durée as invention, "the creation of forms, the continual elaboration of the absolutely new" (Bergson 1911, 14), seems to fit (most forms of) presentism and GBT quite well.

\section{Conclusion: All's Well?}

In this paper, I have promoted a rereading of Bergson. I think that contemporary analytic philosophy of time, especially the debates about persistence and the ontology of time, could benefit from Bergson's insights, and I have tried to illustrate how they could be useful.

The debate about persistence is de facto a debate about how to conceptualise change without a contradiction. Other questions in the context of persistence are disregarded, whether because of an unquestioned paradigm or just because of the focus of the debate. As with all philosophical debates, a position "from outside" can be helpful to overcome these limitations.

Bergson has asserted that objects (and properties) are (mind-dependent) abstractions from an underlying dynamic reality. While the contemporary analytic debate focuses on the horizontal question of reconciling incompatible properties at different times, abstractions concern the horizontal question of which mechanisms are at work to get from the underlying reality to the

22. For example, note that endurantism implies the problematic concept of multilocation only under the assumption of spatialised time.

23. Hence, figure 3 should not be taken at face value, but just as a helpful heuristic. 
relatively isolated systems that we call "objects." This stance incorporates the contemporary problem of persistence into a wider setting. It enables a holistic discussion of the phenomenon of persistence, and, en passant, offers a solution to the horizontal question: As the primary property bearers are not identical over time, no contradiction can arise.

These considerations fit into Bergson's general agenda. Bergson insists that our strong focus on spatialised time ignores the fundamental dynamic reality: pure durée. He explains why spatialised time is so encompassing, but also why for metaphysical purposes we cannot ignore durée. It turns out that spatialised time systemically disadvantages presentism and GBT, and also privileges accounts of persistence with relative definitions of change.

\section{Bibliography}

Balashov, Yuri. 2010. Persistence and Spacetime. Oxford: Oxford University Press.

Benovsky, Jiri. 2007. “On Presentist Perdurantism.” Sats: Nordic Journal of Philosophy. 8(2): 79-88.

Bergson, Henri. 1910. Time and Free Will: An Essay on the Immediate Data of Consciousness. Translated by F. L. Pogson, London: Allen and Unwin.

Bergson, Henri. 1911. Creative Evolution. Translated by Arthur Mitchell. New York: Random House.

Broad, Charlie Dunbar. 1923. Scientific Thought: A Philosophical Analysis of Some of its Fundamental Concepts. London: Taylor \& Francis.

Brower, Jeffrey. 2010. "Aristotelian Endurantism: A New Solution to the Problem of Temporary Intrinsics." Mind 119: 883-905.

Chase, James, and Jack Reynolds. 2010. Analytic Versus Continental: Arguments on the Methods and Value of Philosophy. London: Routledge.

Correia, Fabrice, and Sven Rosenkranz. 2018. Nothing To Come: A Defence of the Growing Block Theory of Time. New York: Springer Verlag.

Costa, Damiano, and Claudio Calosi. 2020. "The Multi-Location Trilemma." Erkenntnis. https://link.springer.com/article/10.1007/ s10670-020-00230-7.

Dainton, Barry. 2017. "Bergson on Temporal Experience and Durée Réelle." In The Routledge Handbook of Philosophy of Temporal Experience, edited by Ian Phillips, 93-106. London: Routledge. 
Fischer, Florian. 2016. "Philosophy of Time: A Slightly Opinionated Introduction." Kriterion: Journal of Philosophy 30(2): 3-28.

Fischer, Florian. 2017. "Persistence Reconsidered: Beyond the Endurance/ Perdurance Distinction." In Logic and Philosophy of Time: Themes from Prior, edited by Per Hasle, Patrick Blackburn and Peter Øhrstrøm, 5166. Aalborg: Aalborg University Press.

Fiocco, Marcello Oreste. 2010. “Temporary Intrinsics and Relativization.” Pacific Philosophical Quarterly 9: 64-77.

Fischer, Florian. 2020. "Limit Deciding Dispositions: A Metaphysical Symmetry-Breaker for the Limit Decision Problem.” Philosophy Kitchen 13: 129-140.

Haslanger, Sally. 1989. "Endurance and Temporary Intrinsics." Analysis 49(3) :119-125.

Johnston, Mark. 1987. “Is There a Problem about Persistence?" Proceedings of the Aristotelian Society 61:107-135.

Lewis, David Kellogg. 1986. On the Plurality of Worlds. Hoboken: Blackwell Publishers.

Meincke, Anne Sophie. 2019. "The Disappearance of Change: Towards a Process Account of Persistence." International Journal of Philosophical Studies 27(1): 12-30.

Meixner, Uwe. 2006. David Lewis. Paderborn: Mentis.

Mellor, David Hugh. 1998. Real Time II. London: Routledge.

Mellor, David Hugh. 2012. Mind, Meaning and Reality. Oxford: Oxford University Press.

Orilia, Francesco. 2016. "Moderate Presentism." Philosophical Studies 173(3): 586-607.

Savitt, Steven. 2002. "On Absolute Becoming and the Myth of Passage." Royal Institute of Philosophy Supplement 50: 153-167.

Seibt, Johanna. 1990. Towards Process Ontology: A Critical Study in the Premises of Substance Ontology. UMI-Publications.

Seibt, Johanna. 2007. "Beyond Endurance and Perdurance: Recurrent Dynamics." In Persistence, edited by Christian Kanzian, 133-65. Heusenstamm: Ontos Verlag.

Sider, Ted. 2001. Four Dimensionalism: An Ontology of Persistence and Time. Oxford: Oxford University Press. 
Vrahimis, Andreas. 2011. "Russell's Critique of Bergson and the Divide Between 'Analytic' and 'Continental Philosophy'." Balkan Journal of Philosophy 3(1):123-134.

William, Ramsey. 2020. "Eliminative Materialism." The Stanford Encyclopaedia of Philosophy. https://plato.stanford.edu/archives/ sum2020/entries/materialism-eliminative/.

University of Siegen - Florian Fischer is currently assistant professor at the University of Siegen. His research focuses on the intersection of time and modality, especially the connection between present and possibility. He is president of the Society for Philosophy of Time (SPoT) and has organised numerous academic events investigating time from various perspectives (see http://s-p-o-t.weebly. com). He is head of the DFG-Network Change and Change-Makers (CCM), which strives to develop a novel concept of persistence that can naturally be applied to a wide array of sciences (see https://ccm.uni-siegen.de).

\begin{abstract}
This paper promotes the incorporation of Bergsonian ideas into contemporary analytic philosophy of time. First, Bergson's claim that objects are ontologically secondary, mind-dependent abstractions from an underlying dynamic reality, opens up the possibility to develop a novel account of persistence, produrantism, perpendicular to the opposing theories, perdurantism and endurantism. Second, Bergson's famous critique of the spatialisation of time explains why the debate about persistence was partial in the first place. Accepting a juxtaposition of multiple times or proto-times, which the implicitly assumed eternalism does, favours accounts of persistence which incorporate a relational definition of change, especially perdurantism.
\end{abstract}

Keywords: persistence, change, produrantism, eternalism, spatialisation of time.

Résumé: Cet article défend l'incorporation des idées bergsoniennes dans la philosophie analytique contemporaine du temps. Premièrement, l'affirmation de Bergson selon laquelle les objets sont des abstractions ontologiquement secondaires, dépendantes de l'esprit d'une réalité dynamique sous-jacente, ouvre la possibilité de développer une nouvelle conception de la persistance, le produrantisme, perpendiculaire aux théories opposées, le perdurantisme et l'endurantisme. Deuxièmement, la célèbre critique de Bergson de la spatialisation du temps explique pourquoi le débat sur la persistance a été partiel en premier lieu. Accepter une juxtaposition de temps multiples ou de prototemps, ce que fait l'éternalisme implicitement supposé, favorise les conceptions de la persistance qui incorporent une définition relationnelle du changement, notamment le perdurantisme.

Mots-clés: persistance, changement, produrantisme, éternalisme, spatialisation du temps. 
